\title{
Industry 4.0 and Modification of Study Programs at the Faculty of Mechanical Engineering, UWB Pilsen
}

\author{
Josef Basl ${ }^{1, *}$, Milan Edl ${ }^{1}$ \\ Faculty of Mechanical Engineering - University of West Bohemia in Pilsen Univerzitní 22, 30614 Pilsen
}

\begin{abstract}
The paper deals with the topic of industry 4.0 and its use in the preparation and teaching of students of the Faculty of Mechanical Engineering, UWB Pilsen. It presents the directions of further development, which is reflected in the modification of subjects and the formulation of a new study program "Intelligent Manufacturing Systems". This activity of the faculty uses the outputs of the project TL 01000081 financed by the Technology Agency of the Czech Republic entitled "Changing the role of the university and innovation of study programs within the phenomenon 4.0 in the fields of machinery, pedagogy and health care".
\end{abstract}

\section{Introduction}

In developed countries, the phenomenon known as "Industry 4.0" has been receiving attention for many years. In these countries, national initiatives, projects or institutions dealing with industry 4.0 are established or supported. In the Czech Republic, the basic document of the national strategy is the "Industry 4.0 National Initiative". The progress and activities of individual countries are evaluated by a number of indices, such as:

- Industry 4.0 Readiness Index from the company Roland Berger (Siepen, 2015).

or

- NRI (Networked Readiness Index) (NRI,2016)

- GII (Global Innovation Index) (Dutta, 2018)

- GCl (Global Competitive Index) (Schwab, 2018)

Available sources suggest that the term industry 4.0 is currently mainly used in Europe. In the United States and English-speaking countries, the term industrial internet is used more, and in some countries, for example, the term smart factory. The German Institute for Industrial Standardization characterizes Industry 4.0 as a merger of real production with the virtual world. A world will emerge in which information technologies are fully integrated into production processes. Systems in production, logistics or services will communicate with each other in a new intelligent way. Thanks to Industry 4.0, production cycles are shortened, customer needs are processed in real time or maintenance is largely automated. The result of all this is smart factories (DIN, 2017).

The European Union (specifically the European Parliament) then understands the term Industry 4.0 as a term for a group of rapid transformations in the design, manufacture, operation and use of systems. The designation 4.0 means that this is the world's fourth industrial revolution (European Union, 2015).

In general, the concept of Industry 4.0 can be characterized as the transformation of production in separate automated factories into fully automated and optimized production environments. Production processes are interconnected vertically and 
horizontally within business systems. To this end, sensors, machines and IT systems are interconnected within a value chain that transcends the boundaries of individual companies. To this end, the CyberPhysical System is being created, which is the basic building block for smart factories.

The topic of industry 4.0 is paid attention not only at the national but also corporate levels. To measure the readiness of enterprises in this direction, a diverse range of models for assessing the readiness of enterprises for the transition to industry 4.0 was created. These models are created both on the campus, in consulting or implementation companies. The main findings obtained from the available high school diploma models indicate that the models are very complex, but do not usually contain a detailed view and address the companywide dimensions at the level of top management.

It is important that within the maturity and readiness models it is not only the technical side of the change and the transition of the company towards industry 4.0 that is evaluated. It is always a strategy and resources for its implementation, and corporate culture, human resources and company employees in general play an important role.

It is precisely in the change of employees' approach to change and new innovations that in the case of innovations in the company and in the effort to achieve the maximum from technical change, one of the main bottlenecks is seen, which is pointed out by E. Goldratt in his book Neccesary but not sufficient.

This is a change in employee behavior that can help facilitate and accelerate innovative actions associated with Industry 4.0. These are both existing employees in companies, but also those who are just preparing for their jobs - i.e. students. The project TL 01000081 "Transformation of the role of the university and innovation of study programs within the phenomenon 4.0 in the fields of mechanical, pedagogical and medical" focused on them, whose main researcher was the Faculty of Mechanical Engineering of the UWB Pilsen.

\subsection{Project objectives}

The Faculty of Mechanical Engineering is one of the three faculties of the UWB Pilsen, which participated in the project in the years 2018 - 2020 together with the Faculty of Education, Medical Studies and Philosophy. This project focused on the need to change and adapt within the phenomenon of 4.0 and educational institutions and the planned completion date is December 2020. When solving the project, the faculty gained more detailed and deeper self-reflection, and tertiary education, zs and the Research Institute of Entrepreneurship and Innovation, z. ú. at the Czech Chamber of Commerce, who also participated in the project. Thanks to the project, the faculty gained access to an extensive data set, which enabled a relevant assessment of the needs of its students and their future employers in the field of education and will enable its timely adaptation to new conditions in education and the labor market.

The main goal of the project was to increase the readiness of graduates. The research focused mainly on the issue of transversal skills and interdisciplinary understanding of individual areas, which are gaining in importance in the changing modern "4.0 society". The need for a change of thinking in all participants in the educational process (school, employer, student and other relevant stakeholders), represented by, for example, the need to jointly set methods and learning outcomes, is then a necessary part of the path to success of a tertiary professional graduate in Society 4.0.

\subsection{Main areas of project solution}

During the project, the following were implemented at the Faculty of Mechanical Engineering:

- three round tables, the implementation of which was carried out within the Industrial Council of the Faculty of Mechanical Engineering of the UWB, whose members are leading representatives of selected companies in the region, representatives of the city of Pilsen and the region and directors of major technical high schools

- analysis of study programs, which included a comparative analysis of the curriculum and content of selected study programs at selected universities, which are close in focus to the study programs of the Faculty of Mechanical Engineering

- questionnaire surveys conducted among students of the Faculty of Mechanical Engineering and also among high school students who are preparing to study at a university and questionnaire surveys conducted among companies in the Pilsen region

\subsubsection{Round tables}

The round tables revealed the need to project smart technologies and trends in Industry 4.0 into the education of students, both by penetrating them into selected existing subjects and by creating completely new subjects focused on trends and applications of Industry 4.0 in mechanical engineering. 
The round tables further confirmed the interest of practitioners to participate in teaching, but also to provide the possibility of practical excursions and internships for students. Representatives of companies also promised to submit bachelor's, master's and event topics. dissertation work connected industry trends 4.0.

There is a strong interest in creating professionally oriented study programs, where companies participate in both teaching and providing internships for students.

Furthermore, the possibility of creating "training workplaces" for students of the Faculty of Mechanical Engineering in the premises of individual companies was discussed, where there would be a stronger professional connection between the student and practice in order to acquire skills and knowledge.

\subsubsection{Analysis of study programs}

If equations are part of the paper, use the following pattern.

The analysis of study programs identified the main competencies that are provided within the study, namely:

- basic technical / professional competences (e.g. mathematics, physics, logic, analysis,...)

- engineering competencies (e.g. construction, technology, materials, system integration,...)

- management competencies (e.g. planning, organizing,...)

- soft skills (e.g. communication, teamwork,...)

The analysis thus clearly pointed to the need for managerial and especially soft skills, in line with the requirements of employers.

\subsubsection{Questionnaire solutions}

Questionnaire surveys included surveys of three types of enterprises according to the standard division in statistical surveys, namely the so-called small enterprises (up to 49 employees), mediumsized enterprises (50-249 employees) and large enterprises (250+). Due to the complexity of collection and the minimal implementation of P4.0 in small companies so far, it was agreed to conduct research only in medium and large companies, which are defined as engineering. The actual collection took place by a combination of CAPI and CATI methods in September and October 2019. With the help of CATI, 311 questionnaires were collected by people from the management of medium-sized companies (of which 184 are directly top managers such as CEO, production director, etc.). Out of a total of 138 medium-sized companies, we received answers in the management of 114 companies (83\% return). In the case of large companies, CAPI collected at least one questionnaire in the management of each of the 45 companies, a total of 167 questionnaires in the management of large companies (108 of them directly by top managers). In total, we interviewed 478 people in the management of medium and large companies (of which 292 were top managers).

\subsection{Important outputs of the project - modification of subjects and study programs at the Faculty of Mechanical engineering}

On the basis of the round tables, analyzes of study programs and questionnaire surveys among companies, innovations and modifications of study subjects were started, as well as the design of a new study program. The proposed modifications are partly already included in the existing study programs and contain

1.3.1 Modification and modernization of existing subjects

a) Modifications of the content of existing subjects of the faculty, such as Business Information Systems, Digital Enterprise and Virtual Reality, Fundamentals of Robotics and Modern Technologies

b) Use of new software and technical solutions for production planning and control - SW tools APS (Advanced Planning and Scheduling) and MES (Manufacturing Execution System) and for automation of administrative and control processes of mechanical engineering - SW tool RPA (Robotic Process Automation)

c) Use of a manipulation robot for the preparation of its digital twin

\subsubsection{Creation of new subjects}

The outputs of the project pointed to the need to create new study subjects.

a) The subject Application of Industry 4.0 in Mechanical Engineering is newly taught in this semester

b) The subjects Digital Business Transformation Trends, Specialized Practice and Specialized Excursion are being prepared for accreditation

\subsubsection{Preparation of accreditation of a new study program}

One of the important outputs of the project is the preparation of the accreditation of a new study program called Smart manufacturing systems with two specializations:

\section{- Manufacturing Machines and Technologies}

\section{- Digital Manufacturing}

The study program will be accredited for the field of mechanical engineering as a follow-up master's program in cooperation with the Faculty of Applied Sciences of the UWB Pilsen specializing in the field of artificial intelligence, cybernetics, data processing and business analytics.

Following the identified requirements, the graduate of this study program will focus on proving professional and theoretical knowledge in 
the field of methods and methodologies for digital transformation and innovation of companies. He will be able to independently orientate himself in the offer and market trends. He will be able to actively use the main application packages within the enterprise architecture of an engineering (industrial) company and will be able to actively participate in innovative digital transformation projects with the subsequent management of such projects and teams. The expected start of teaching the new study program is planned for the beginning of the academic year 2021/2022.

\section{Summary}

The results of the project were reflected not only in the modifications of study programs and individual subjects. The topic of industry 4.0 and the phenomenon 4.0 in general is one of the key factors for the further development of the Faculty of Mechanical Engineering and will be included in the prepared five-year plan, the so-called Strategic Plan of the Faculty for the period 2021-2025. At the same time, in connection with industry 4.0, the Faculty is fully involved in the development of the region, e.g. by participating in the creation and implementation of RIS3 strategy, within the activities of the smart region but also in the preparation of a digital innovation hub supporting digital transformation in the next EU multi-annual planning period 20212027.

\section{Acknowledgments}

Project TL01000081 Transformation of the role of the university and innovation of study programs within the phenomenon 4.0 in the areas of mechanical, pedagogical and medical is co-financed with the state support of the Technology Agency of the Czech Republic within the Éta Program.

\section{References}

[1] CARTWRIGHT, P.: Manufacturing gets personal in Industry 5.0, https://www.raconteur.net/ technology/ manufacturing-gets-personal-industry-5-0

[2] DELOITTE. Industry 4.0: Challenges and solutions for the digital transformation and use of exponential technologies [online]. 2015 [cit. 2017-03-13]. Available: https://www2.deloitte.com/content/dam/Deloitte/ ch/Documents/manufacturing/ch-en-manufacturingindustry-4-0-24102014.pdf

[3] DIN. What is Industry 4.0? In: DIN - German Institute for Standardization [online]. 2017 [cit. 2017-03-13]. Available: http://www.din.de/en/innovation-and-research/ industry-4-0/what-is-industry-4-0

[4] DUTTA S., LANVIN, B., Wunsch-Vincent, S.: Global Innovation Index 2018 Energizing the World with Innovation, 11th Edition, ISSN 2263-3993 ISBN 979-10-95870-09-8, https:// www.globalinnovationindex.org/gii-2018-report

[5] EUROPEAN COMMISSION. Coordination of European, national \& regional initiatives. In: European Commission [online]. 2016 [cit. 2017-03-13]. Available: https://ec.europa. eu/digital-single-market/en/cordination-europeannational-regional-initiatives

[6] EUROPEAN UNION. Industry 4.0: Digitalisation for productivity and growth. In: European Parliament [online]. 2015 [cit. 2017-03-13]. Available: http://www.europarl. europa.eu/RegData/etudes/BRIE/2015/568337/EPRS_ BRI(2015)568337_EN.pdf

[7] GANZARAIN, J., ERRASTI, N.: Stage maturity model in SME towards Industry 4.0, Jouŕnal of Engineering and Management, 2016.

[8] GLOBAL TRENDS 2030: Alternative Worlds, National Intelligence Council, 2012, https://globaltrends2030. files.wordpress.com/2012/11/global-trends-2030november2012.pdf Accessed: 2016-04-27

[9] KENNEDY, Scott. Made in China 2025. In: Center for Strategic and International Studies [online]. 2015 [cit. 2017-03-13]. Available: https://www.csis.org/analysis/made-china-2025

[10] MACDOUGALL, William. Industrie 4.0: Smart Manufacturing for the Future. In: GTAI [online]. Germany Trade and Invest, 2014 [cit. 2017-03-13]. Available: https://www.gtai.de/ GTAI/Content/EN/Invest/_SharedDocs/Downloads/GTAI/ Brochures/Industries/industrie4.0-smart-manufacturingfor-the-future-en.pdf? $v=8$

[11] MAŘíK, Vladimír. Průmysl 4.0: výzva pro Českou republiku. Praha: Management Press, 2016. ISBN 978-80-7261-440-0.

[12] OECD: OECD Science, Technology and Industry Scoreboard 2017: The digital transformation, OECD Publishing, Paris, https://doi.org/10.1787/9789264268821-en

[13] PESSL, E., ROMINA, S., MAYER, B.: Roadmap Industry 4.0 Implementation Guideline for Enterprises, International Journal of Science, Technology and Society, 2017

[14] ROLANDBERGER.THINKACT:Industry 4.0-thenewindustrial revolution [online]. 2014 [cit. 2017-03-13]. Available: https:// www.rolandberger.com/publications/publication_pdf/ roland_berger_tab_industry_4_0_20140403.pdf

[15] SCHWAB, K.: The Global Competitiveness Report 2018, World Economic Forum, 2018, ISBN-13: 978-92-95044-76-0, http://www3.weforum.org/docs/GCR2018/05FullReport/ TheGlobalCompetitivenessReport2018.pdf

[16] SIEPEN, S. et all.: INDUSTRY 4.0 The role of Switzerland within a European manufacturing revolution, Roland 
Berger Stretegy consultants GmbH, 2015, https://www. rolandberger.com/en/Publications/Industry-4.0---thenew-industrial-revolution.html

[17] MATESOVA, P. S.: Consequences of Industry 4.0 in Business and Economics. Economies, 3(46), 2018.

[18] HEDVICAKOVA M., KRAL M., Level of Industry Automation 4.0 in the Czech Republic and Impact on Unemployment. European Financial Systems 2018, 2018, 160.

[19] VRCHOTA, J., VOLEK, T., \& NOVOTNA, M.: Factors Introducing Industry 4.0 to SMES. Social Sciences, 8(5), p.130, 2019.

\section{$\mathbf{T} \quad \mathbf{A}$ Č $\quad \mathbf{R}$ university and innovation of study programs within the phenomenon 4.0 in the areas of mechanical, pedagogical and medical is co-financed with the state support of the Technology Agency of the Czech Republic within the Éta Program}

Project TL01000081 Transformation of the role of the

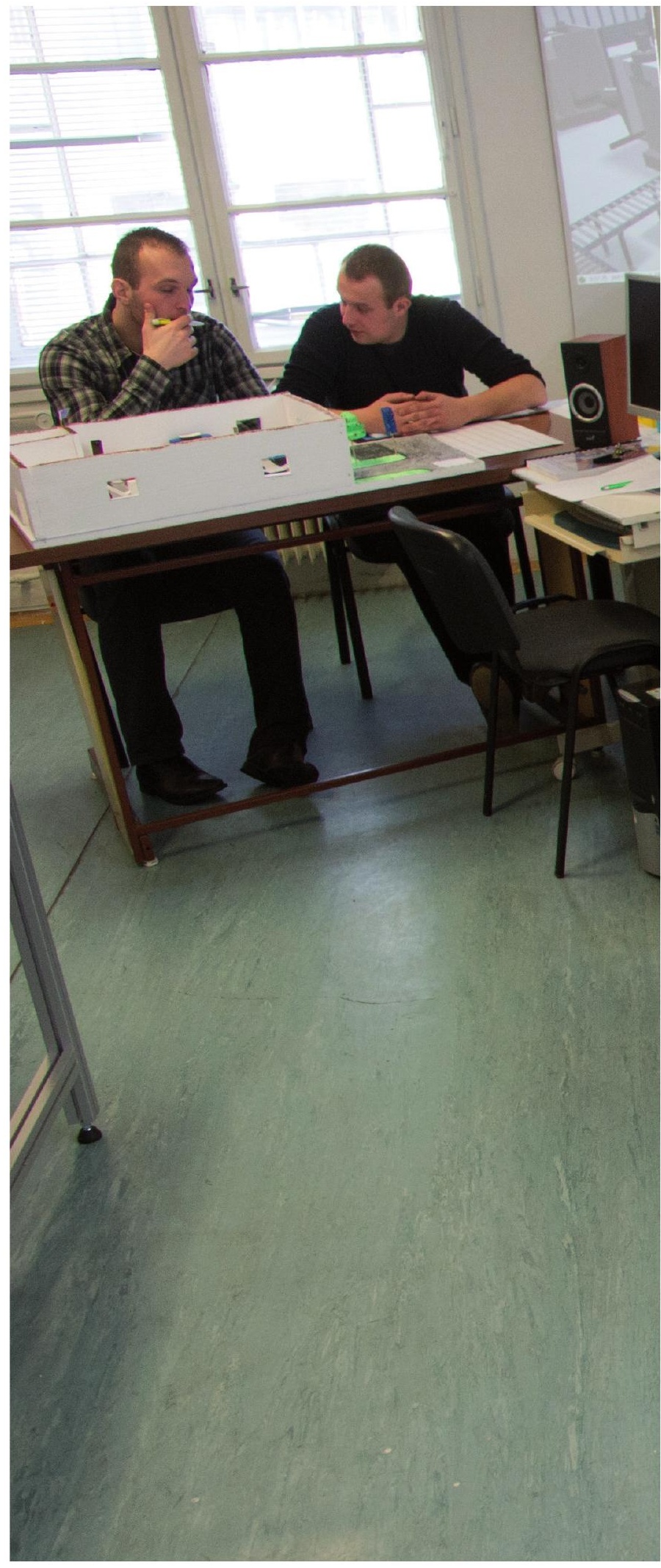

